\title{
Hospital Emergency Management of Emerging Infectious Disease using Instant Communication Technology - ERRATUM
}

\author{
Chih-Hao Lin, MD; (i) Chih-Chia Hsieh, MD; Chih-Hsien Chi, MD
}

\author{
Department of Emergency Medicine, National \\ Cheng Kung University Hospital, College of \\ Medicine, National Cheng Kung University, \\ Tainan, Taiwan \\ Correspondence: \\ Chih-Hao Lin, MD \\ 70403, No.138, Shengli Road, \\ North District, Tainan City, Taiwan \\ Department of Emergency Medicine \\ National Cheng Kung University Hospital, \\ College of Medicine \\ National Cheng Kung University \\ Tainan, Taiwan \\ E-mail: emergency.lin@gmail.com
}

Conflicts of interest/funding: The authors report no conflicts of interest. No financial support was granted.

Keywords: communication; COVID-19; hospital emergency management; infectious disease; erratum

Received: April 13, 2020

Accepted: May 6, 2020

doi:10.1017/S1049023X20000849

(C) The Author(s), 2020. Published by Cambridge University Press on behalf of World Association for Disaster and Emergency Medicine. This is an Open Access article, distributed under the terms of the Creative Commons Attribution licence (http://creativecommons.org/licenses/by/4.0/), which permits unrestricted re-use, distribution, and reproduction in any medium, provided the original work is properly cited.
https://doi.org/10.1017/S1049023X20000618; Published by Cambridge University Press, 21 May 2020.

Lin $\mathrm{CH}$, Hsieh CC, Chi $\mathrm{CH}$. Hospital emergency management of emerging infectious disease using instant communication technology - ERRATUM. Prehosp Disaster Med. 2020;35(4):473.

In the original publication of this article, the year in the received date appeared incorrectly. The correct history dates for this article are:

Received: April 13, 2020

Accepted: May 6, 2020

The publisher apologizes for this error.

\section{Reference}

1. Lin $\mathrm{CH}$, Hsieh $\mathrm{CC}$, Chi $\mathrm{CH}$. Hospital emergency management of emerging infectious disease using instant communication technology. Prehosp Disaster Med. 2020;35(4):XX-XX. 